\title{
EDITORIAL
}

\section{What can we learn about airway smooth muscle from the company it keeps?}

\author{
S. Siddiqui, F. Hollins and C.E. Brightling
}

I n severe and fatal asthma dramatic changes in airway structure have been described, collectively referred to as remodelling $[1,2]$. Current dogma dictates that remodelling reflects aberrant repair in response to ongoing inflammation and injury. However, the interplay between inflammation and remodelling, and, more importantly, between airway structure and function remains elusive, such that we remain uncertain whether these changes protect the airways from the effects of inflammation or are integral to disease progression. To begin to unravel this conundrum we need to recognise the complexity and heterogeneity of asthma.

The asthma paradigm comprises several domains, including ongoing symptoms, the presence of variable airflow obstruction and airway hyperresponsiveness. Together with such disordered airway physiology, most subjects with asthma have evidence of a chronic inflammatory response that is typically, but not exclusively, eosinophilic, with the presence of mast cells within the airway smooth muscle bundle [3-5]. In addition, there is often evidence of structural remodelling of the airway wall with thickening of the reticular lamina, mucus gland hyperplasia, increased vasculature, and increased airway smooth muscle hyperplasia and hypertrophy. Importantly, some features of remodelling, particularly thickening of the lamina reticularis, can occur early on in disease and even in some children prior to the onset of asthma [6]. In contrast, other aspects of the remodelling process have been associated with disease duration [7].

In addition to structural and inflammatory cells, the airway wall is comprised of extracellular matrix, the composition of which varies between different compartments in the airway wall, between asthma versus health, and across disease severity. This matrix is not a benign bystander that simply constitutes the scaffold to build airway structures and allow inflammatory cell trafficking, but can alter the biophysical properties of the airway wall and modulate cell function.

The increasing recognition of the importance of the extracellular matrix composition and its interactions with cells has

Institute for Lung Health, Dept of Infection, Inflammation and Immunity, University of Leicester, Leicester, UK.

STATEMENT OF INTEREST: A statement of interest for C.E. Brightling can be found at www.erj.ersjournals.com/misc/statements.shtml

CORRESPONDENCE: C.E. Brightling, Institute for Lung Health, University of Leicester, Glenfield Hospital, Groby Road, Leicester, LE3 9QP, UK. Fax: 44 1162502787. E-mail: ceb17@le.ac.uk driven research into determining the make up of the extracellular matrix in different airway compartments. In this edition of European Respiratory Journal, ARAUJO et al. [8] describe the extracellular matrix components and regulators within the airway smooth muscle bundle in fatal asthma, subjects with asthma that died of other causes and controls. They found that in fatal asthma: elastin fibres, fibronectin, and matrix metalloproteinase (MMP)-9 and -12 were increased in the airway smooth muscle bundle in large airways; and only elastic fibres were increased in the airway smooth muscle bundle in small airways. These observations add to our increasing knowledge of the different extracellular matrix profile in the airway smooth muscle in asthma versus health, and add to the pattern observed in the lamina propria and lamina reticularis summarised in figure 1. Critically, can we predict how these patterns of extracellular matrix distribution will impact on airway function?

Airway calibre is determined dynamically by the balance between forces driving constriction (namely, airway smooth muscle) and forces maintaining patency (such as lung elastic recoil), and is moderated by the relative hysteresis of airways and lung parenchyma. In fatal asthma, elastic fibres are decreased in the airway periphery and in the subepithelium, and their loss leads to loss of compliance $[9,10]$. Subepithelial fibrosis might prevent airway narrowing and increase airway wall stiffness, resistance to compression and tension. In severe and fatal asthma, the proteoglycans versican, biglycan and lumican are increased in the lamina propria and around the airway smooth muscle [11-13], although they are not increased within the airway smooth muscle-bundle [12]. The increased elastic fibres in the airway smooth muscle bundle and the distribution of proteoglycans may increase resistance to airway wall deformation and provide a preload to the airway smooth muscle that opposes its shortening and, therefore, airway narrowing. The effect of extracellular matrix composition on airway hysteresis is uncertain but, interestingly, recent evidence does support a role for mast cell-airway smooth muscle interactions in the bronchodilator/constrictor response to a deep breath [14]. The potential effect on airway function of extracellular matrix composition in different airway compartments is summarised in figure 1. Interestingly, the increased MMP-9 and -12 expression in the airway smooth muscle bundle provides evidence that extracellular matrix turnover is a dynamic process and therefore may be amenable to therapy. In addition to its effect on the structure of the airway wall, extracellular matrix may also exert effects on cell function, particularly airway smooth muscle. 


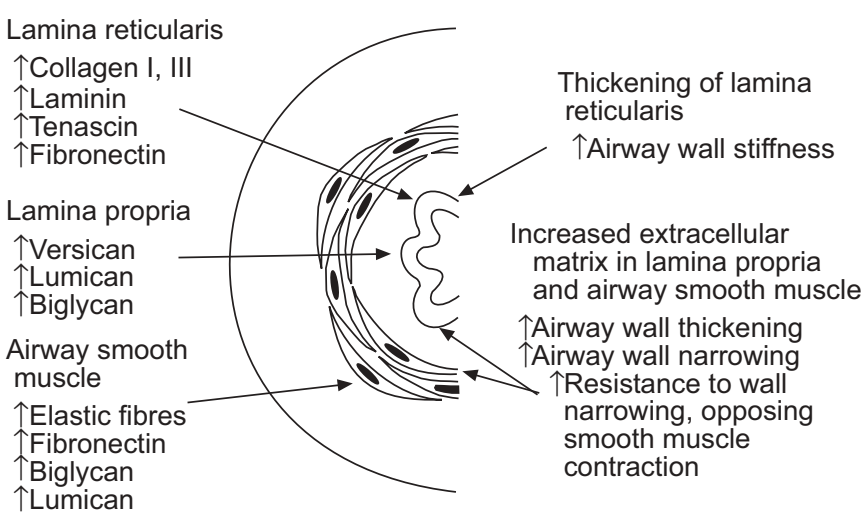

FIGURE 1. An illustration of the changes in extracellular matrix composition in asthma and the associated potential physiological effects.

Increased airway smooth muscle mass, well recognised within both large and small airway walls, is evident in both fatal and nonfatal cases of asthma [15], and is a major determinant in the development of persistent airway obstruction in chronic disease [16]. This increased airway smooth muscle mass may be due to increased airway smooth muscle proliferation, survival or recruitment of airway smooth muscle progenitors [17]. In vitro asthmatic airway smooth muscle proliferates at an increased rate [18], which is in part due to exaggerated metabolic activity [19] and altered matrix deposition [20]. Extracellular matrix proteins promote airway smooth muscle survival, and fibronectin and collagen III and V enhance airway smooth muscle migration [21]. Therefore, the increased fibronectin expression in the airway smooth muscle bundle observed by ARAUJO et al. [8] may be critical to promoting airway smooth muscle hyperplasia. Extracellular matrix composition can also influence airway smooth muscle contraction (reviewed in [22]). In addition, airway smooth muscle cells cultured from subjects with asthma are hypersecretory compared with cells from healthy donors, which is in part due to the autocrine secretion of fibronectin [23]. Therefore, extracellular matrix can promote airway smooth muscle survival, proliferation, migration, contraction and secretion.

To date, most studies have focussed on specific features of remodelling in tissue, such as extracellular matrix composition, and some have related this to lung function or airway hyperresponsiveness. In order to further appreciate the role of remodelling, and the contribution from extracellular matrix on airway structure and function, there is a need to undertake multi-modality studies [24]. Advances in noninvasive imaging, such as high-resolution CT, or invasive imaging techniques, such as in vivo confocal fluorescence microscopy to detect changes in the autofluorescence spectra of deposited matrix in the airway wall [25], as well as methods of assessing bronchial wall thickening, such as endobronchial ultrasound and optical coherence tomography [26], provide us with detailed information on geometry. These data need to be coupled with a detailed immunopathological assessment of the same individual in order to determine the relative impact on airway physiology of airway inflammation, the pattern of remodelling and altered airway geometry. Importantly, such studies need to consider going beyond spirometry, which is a blunt tool and may fail to capture the effects of airway structure on airway mechanics, such as hysteresis. In addition to these approaches, it is important to include longitudinal assessments to allow researchers to unpick these complex structure-function relationships.

Critically, we need to know whether modifying extracellular matrix composition and airway remodelling in general impacts upon asthma symptoms, exacerbations and disease progression. There is limited data on the effects of current therapies on extracellular matrix composition. In stable disease, inhaled corticosteroid therapy for 6 weeks did not affect collagen III expression [27], and in an allergen challenge study, extracellular matrix composition increased in response to allergen and was augmented rather than inhibited by corticosteroids [13]. Therefore, corticosteroids may paradoxically increase certain extracellular proteins. The advent of thermoplasty brings with it tremendous enthusiasm that we may have a tool to modify airway remodelling [28]. Although the early studies show some promise, it is too premature to know if this technique will realise its potential, and to date, it is unclear whether it alters extracellular matrix composition in the airway. Parallels have been drawn between asthma and lung fibrosis, leading some authors to question whether asthma is a fibrotic disease [29]. Therefore, advances in the management of lung fibrosis may shed light on potential therapies to modulate airway remodelling in asthma. However, perhaps before we focus on normalising extracellular matrix composition we need to stand back and ask again whether altered extracellular matrix composition in the airway smooth muscle bundle and in the airway in general is good or bad in the pathogenesis of asthma. Indeed, we are still uncertain whether we can judge airway smooth muscle in asthma by the company it keeps. Perhaps we should encourage aspects of remodelling whilst discouraging others; which we should chose remains to be determined.

\section{REFERENCES}

1 James AL, Wenzel S. Clinical relevance of airway remodelling in airway disease. Eur Respir J 2007; 30: 134-155.

2 Mauad T, Bel EH, Sterk PJ. Asthma therapy and airway remodelling. J Allergy Clin Immunol 2007; 120: 997-1009.

3 Wardlaw AJ, Brightling CE, Green R, Woltmann G, Bradding P, Pavord ID. New insights into the relationship between airway inflammation and asthma. Clin Sci 2002; 57: 875-879.

4 Brightling NEJM, Brightling CE, Bradding $\mathrm{P}$, et al. Mast cell infiltration of airway smooth muscle in asthma. $N$ Engl J Med 2002; 346: 1699-1705.

5 Saha SK, Berry M, Parker D, et al. Increased sputum and bronchial biopsy IL-13 expression in severe asthma. J Allergy Clin Immunol 2008; 121: 685-691.

6 Sagalani S, Payne DN, Zhu J, et al. Early detection of airway wall remodeling and eosinophilic inflammation in preschool wheezers. Am J Respir Crit Care Med 2007; 176: 858-864.

7 Siddiqui S, Sutcliffe A, Shikotra A, et al. Vascular remodelling is a feature of asthma and non-asthmatic eosinophilic bronchitis. J Allergy Clin Immunol 2007; 120: 813-819. 
8 Araujo BB, Dolhnikoff M, Silva LFF, et al. Exctracellular matrix components and regulators in the airway smooth muscle in asthma. Eur Respir J 2008; 32: 61-69.

9 Mauad T, Xavier AC, Saldiva PH, Dolhnikoff M. Elastosis and fragmentation of fibres of the elastic system in fatal asthma. Am J Respir Crit Care Med 1999; 160: 968-975.

10 Mauad T, Silva LF, Santos MA, et al. Abnormal alveolar attachments with decreased elastic fibre content in distal lung in fatal asthma. Am J Respir Crit Care Med 2004; 170: 857-862.

11 Matsushita MM, Silva LFF, Santos MA, et al. Airway proteoglycans are differentially altered in fatal asthma. J Pathol 2005; 207: 102-110.

12 Pini L, Hamid Q, Shannon J, et al. Differences in proteoglycan deposition in the airways of moderate and severe asthmatics. Eur Respir J 2007; 29: 71-77.

13 De Kluijver J, Schrumpf JA, Evertse CE, et al. Bronchial matrix and inflammation respond to inhaled steroids despite ongoing allergen exposure in asthma. Clin Exp Allergy 2005; 35: 1361-1369.

14 Slats AM, Janssen K, van Schadewijk A, et al. Bronchial inflammation and airway responses to deep inspiration in asthma and chronic obstructive pulmonary disease. Am J Respir Crit Care 2007; 176: 121-128.

15 Carroll N, Elliot J, Morton A, James A. The structure of large and small airways in nonfatal and fatal asthma. Am Rev Respir Dis 1993; 147: 405-410.

16 Benayoun L, Druilhe A, Dombret MC, Aubier M, Pretolani M. Airway structural alterations selectively associated with severe asthma. Am J Respir Crit Care Med 2003; 167: 1360-1368.

17 Kaur D, Saunders R, Berger P, et al. Airway smooth muscle and mast cell-derived CCL19 mediate airway smooth muscle migration and repair in asthma. Am J Respir Crit Care Med 2006; 174: 1179-1188.

18 Johnson PR, Roth M, Tamm M, et al. Airway smooth muscle cell proliferation is increased in asthma. Am J Respir Crit Care Med 2001; 164: 474-477.
19 Trian T, Benard G, Begueret $\mathrm{H}$, et al. Bronchial smooth muscle remodeling involves calcium-dependent enhanced mitochondrial biogenesis in asthma. J Exp Med 2007; 204: 3173-3181.

20 Johnson PR, Burgess JK, Underwood PA, et al. Extracellular matrix proteins modulate asthmatic airway smooth muscle cell proliferation via an autocrine mechanism. J Allergy Clin Immunol 2004; 113: 690-696.

21 Parameswaran K, Radford K, Zuo J, Janssen LJ, O’Byrne PM, Cox PG. Extracellular matrix regulates human airway smooth muscle cell migration. Eur Respir J 2004; 24: 545-551.

22 Zhang W, Gunst SJ. Interactions of airway smooth muscle cells with their tissue matrix-implications for contraction. Proc Am Thorac Soc 2008; 5: 32-39.

23 Chan V, Burgess JK, Ratoff JC, et al. Exracellular matrix regulates enhanced eotaxin expression in asthmatic airway smooth muscle cells. Am J Respir Crit Care Med 2006; 174: 379-385.

24 Bergeron C, Tulic MK, Hamid Q. Tools used to measure airway remodelling in research. Eur Respir J 2007; 29: 596-604.

25 Thiberville L, Moreno-Swirc S, Vercauteren T, Peltier E, Cave C, Bourg Heckly G. In vivo imaging of the bronchial wall microstructure using fibered confocal fluorescence microscopy. Am J Respir Crit Care Med 2007; 175: 22-31.

26 Coxson HO, Quiney B, Sin DD, et al. Airway wall thickness assessed using computed tomography and optical coherence tomography. Am J Respir Crit Care Med 2008; [Epub ahead of print PMID: 18310475].

27 Bergeron C, Hauber HP, Gotfried M, et al. Evidence of remodelling in peripheral airways of patients with mild to moderate asthma: effect of hydrofluoroalkane-flunisolide. J Allergy Clin Immunol 2005; 116: 983-989.

28 Cox G, Thomson NC, Rubin AS, et al. Asthma control during the year after bronchial thermoplasty. $N$ Engl J Med 2007; 356: 1327-1337.

29 Roberts C. Is asthma a fibrotic disease? Chest 1995; 107: Suppl. 3, 111S-117S. 